\title{
SAFT VES16 SOLUTION FOR SMALL GEO
}

\author{
Emmanuel Bonneau ${ }^{(1)}$, Stéphane Remy ${ }^{(1)}$ \\ (1) Saft, Space and Defence Division, Rue Georges Leclanché 86060 Poitiers - France, \\ Email: emmanuel.bonneau@saftbatteries.com, stephane.remy@saftbatteries.com
}

\begin{abstract}
At the end of 2008, Saft has designed the VES16 cell [1], a new Li-ion cell aiming to address Low Earth Orbit (LEO) satellite market.

In the frame of ESA GSTP 5.2 activity, Saft has then developed and successfully qualified [2] a range of batteries based on the VES16 cell and its autonomous Simplified Balancing System (SBS), targeting both LEO and Geostationary Earth Orbit (GEO) missions
\end{abstract}

The very good performance of the VES16 cell demonstrated in GEO mission cycling configuration allows now Saft to propose it on small geostationary spacecraft with typical power lower than $10 \mathrm{~kW}$, offering a simpler, autonomous and competitive solution compared to Saft high capacity cells solutions with VES180 qualified on several telecommunication spacecraft.

This paper will present the design of the VES16, its performance for GEO mission, the configuration of batteries based on this cell, with their benefit and drawbacks, and will detail two current GEO applications using VES16 batteries.

\section{VES16 LI-ION CELL DESIGN}

The VES16 Li-ion cell has been designed by Saft especially for space applications.

The development was conducted with the support and partnership of CNES French agency, until the qualification successfully completed in July 2011.

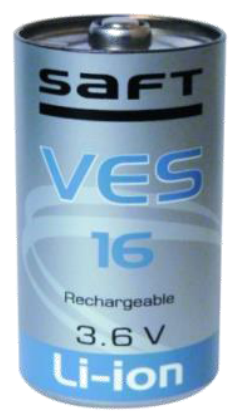

Figure 1. VES16 Li-ion cell.
The design of the VES16 cell is based on Nickel Cobalt Aluminium (NCA) electrochemistry. The VES16 cell has then a NCA positive electrode and a graphite negative electrode, and is filled with a $\mathrm{LiPF}_{6}$ based electrolyte.

It combines benefits and heritage of low capacity MPS Li-ion cells in term of size and mechanics, and advantages of Nickel oxide base Li-ion chemistry of VES100-140-180 cells.

Interfaced in a D-size, the cell has a can in stainless steel connected to the negative polarity whereas the positive polarity is on the top of the cell.

Regarding safety aspects, a circuit breaker is included in the cell design as part of the positive terminal for protection against abusive conditions. Only the internal cell pressure is used to detect failures and to trigger the cell open circuit. This activation is non-reversible. This embedded device is very useful to architect the battery in SP configuration.

As a second barrier, each cell is equipped with a weakened cover that prevents the cell to burst (leak before burst design), operating when the internal pressure rises above the average 27 bar absolute pressure.

Its main characteristics are as follows:

\begin{tabular}{l|l|}
\hline Dimensions $(\varnothing \times \mathrm{H})$ & $33 \times 60 \mathrm{~mm}(\mathrm{D}$-size $)$ \\
\hline Weight & $\leq 114.4 \mathrm{~g}$ \\
\hline Volume & $0.051 \mathrm{dm}^{3}$ \\
\hline Voltage range & {$[2.7 ; 4.1] \mathrm{V}$} \\
\hline Nominal capacity $(\mathrm{C})$ & $4.5 \mathrm{Ah}$ on $4.1-2.7 \mathrm{~V} @ \mathrm{C} / 2,20^{\circ} \mathrm{C}$ \\
\hline Nominal energy & $16 \mathrm{Wh}$ on $4.1-2.7 \mathrm{~V} @ \mathrm{C} / 2,20^{\circ} \mathrm{C}$ \\
\hline Specific energy & $>140 \mathrm{Wh} / \mathrm{kg}$ \\
\hline Internal resistance & $\leq 35 \mathrm{~m} \Omega @ 20 \%$ DoD \\
\hline Operating temperature & {$[+10 ;+30]{ }^{\circ} \mathrm{C}$} \\
\hline Mech. design margins & $\mathrm{EWR} \& \mathrm{ECSS}$ compliant \\
\hline
\end{tabular}

Table 1. VES16 Li-ion main characteristics. 


\section{VES16 PERFORMANCE FOR GEO MISSIONS}

\subsection{Calendar losses}

The design of the VES16 cell is based on similar electrochemistry as VES100-140-180 cells, which follows the same calendar ageing laws induced by lithium corrosion at the negative electrode.

Fig. 2 below presents the capacity fading of the VES16 cell versus time and for different temperatures. The average data obtained from results of the calendar lifetests are represented with dots.

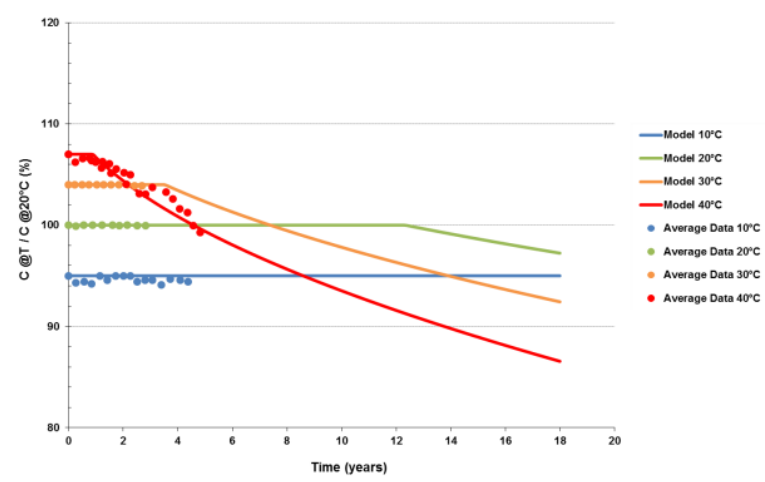

Figure 2. Capacity fading versus time \& temperature.

For the VES16 cell, the capacity degradation at $+20^{\circ} \mathrm{C}$ appears only after more than 12 years, once that the complete Lithium reserve included in the negative electrode has been consumed.

This makes it particularly suitable to extended lifetimes involving longer on-ground storage periods and in-orbit Geostationary Earth Orbit (GEO) mission durations.

\subsection{GEO mission cycling performance}

Accelerated GEO life-tests performed at $60 \%, 70 \%$ and $80 \%$ of Depth of Discharge (DoD) have demonstrated the very good performance of the VES16 cell for GEO applications.

As an example, accelerated GEO life-test without solstice (worst case compared to real-time or semiaccelerated life-test) at $80 \% \mathrm{DoD}$ and End-Of-Charge Voltage (EOCV) of $4.05 \mathrm{~V}$ shows about only $2 \%$ of energy losses after 30 seasons (15 years of GEO mission) and less than $4 \%$ after 45 seasons completed, as shown on Fig. 3 below.

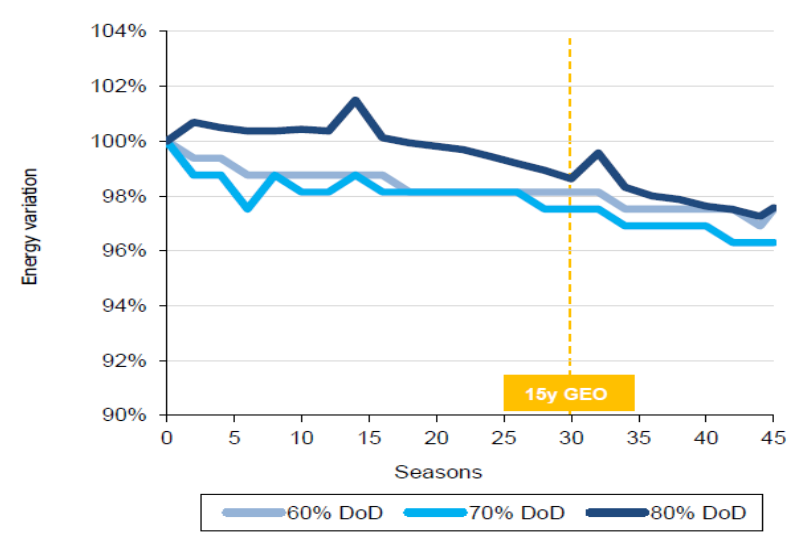

Figure 3. Variation of energy in check-ups.

Moreover the VES16 offers a very good stability of the End-Of-Discharge Voltage (EODV) during the $23^{\text {rd }}$ discharge $(72 \mathrm{~min})$ of eclipse seasons, as shown on Fig. 4, Fig. 5 and Fig. 6 below, respectively during GEO cycling at $60 \%, 70 \%$ and $80 \%$ DoD.

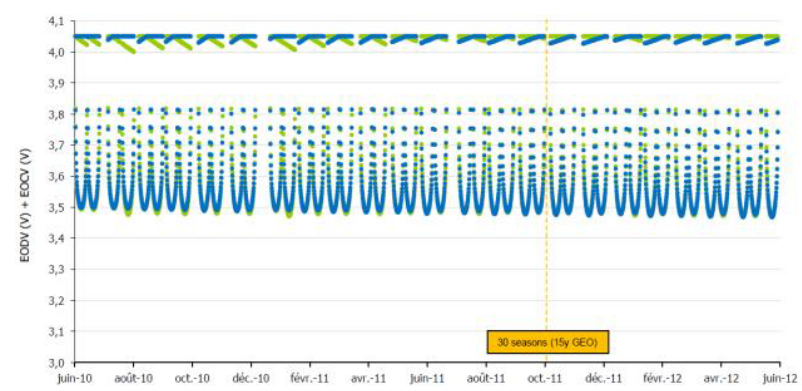

Figure 4. EODV evolution during VES16 accelerated GEO cycling at $60 \% \mathrm{DoD}$.

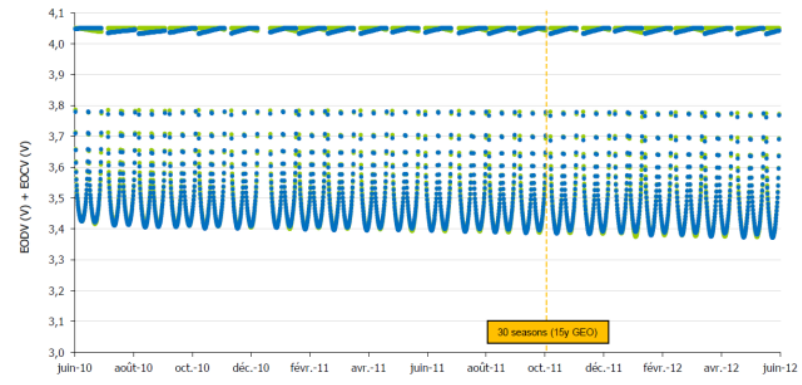

Figure 5. EODV evolution during VES16 accelerated GEO cycling at $70 \%$ DoD.

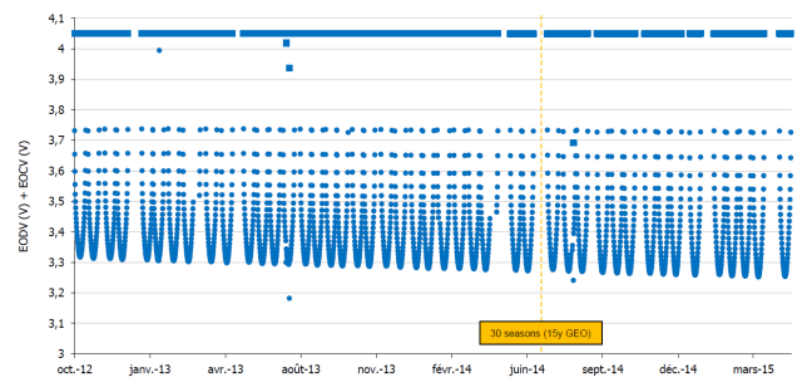

Figure 6. EODV evolution during VES16 accelerated GEO cycling at $80 \%$ DoD. 
Semi-accelerated life-test has also recently started for analysing the performance of VES16 cells for GEO cycling with additional Plasmic Propulsion System (PPS) cycles and demonstrating its ability for full GEO electric propulsion spacecraft [3].

It consists in two additional PPS cycles at 10\%@20 $0{ }^{\circ} \mathrm{C}$ during equinox periods (two GEO cycles per day at $80 \%$ DoD) and six PPS cycles at $20 \%$ DoD per day during solstice periods.

After 14 seasons, the results show that the effect of PPS discharge on the GEO cycling tests are negligible in term of energy loss (see Fig. 7), EoDV drop and internal resistance increase, perfectly line with predictions.

This confirms the excellent ability of VES16 cell to sustain GEO PPS missions.

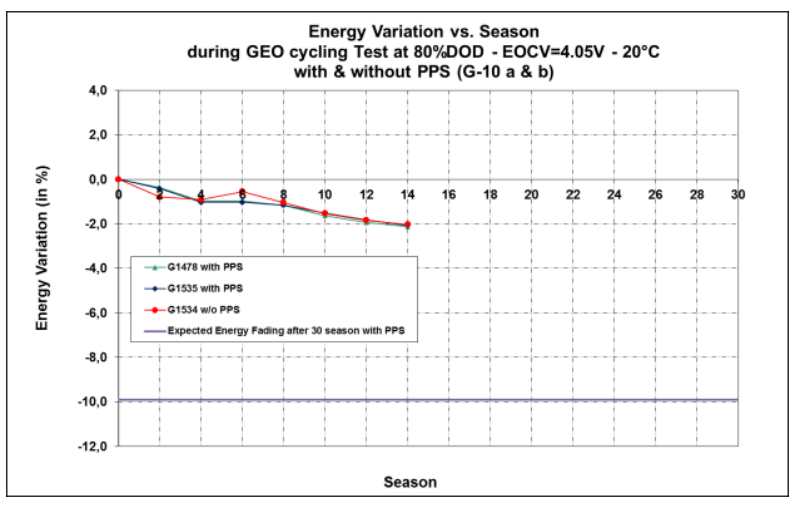

Figure 7. Energy variation in GEO cycling with \& without PPS.

\section{VES16 BATTERIES CONFIGURATION}

The VES16 batteries design is based on Serial-Parallel (S-P) architecture, compared to the Parallel-Serial (P-S) architecture of VES100-140-180 batteries design.

Cells are first connected in series to constitute strings and obtain the required battery voltage.

Strings are then connected in parallel to reach the capacity needed for mission.

This architecture, interesting for small cells capacity, is especially adapted to configurations with $\mathrm{P}>\mathrm{S}$ and compatible of unregulated bus.

But this also implies to have safety devices to put in open circuit the string in failure in order to prevent the risks associated to abusive conditions.

Three levels are implemented at cell level, comprising:

- $\quad$ separator shut down effect,

- a circuit breaker inside the cell on the positive connexion,

- two weakenings on the cover for the venting system.
Due to the S-P architecture, a cell in failure leads in the worst case to loss the associated string and so a part of the battery capacity, compared to the P-S architecture where this will lead to a reducing of the battery voltage. It has been shown by test [4] during the unlikely event of a soft short, that the behaviour of the battery can be either a stabilization of the overcharged and overdischarged cells in a sort of steady state, or in the cell opening leading to the loss of one string.

Regarding electronics, a Simplified Balancing System (SBS), implemented across each cell, is used to balance cell voltages within each string at the end of charge and to reduce the cell degradation by limiting excursion beyond 4.1 Volts.

Balancing is made by draining a portion of the charge current above a voltage threshold.

Fig. 8 below gives an example of balancing done on the GSTP-5 10S5P VES16 Battery during GEO cycling after a string was voluntarily unbalanced (voltage spread within the string was at least $50 \mathrm{mV}$ ). Cell voltages convergence and stabilization $(15 \mathrm{mV}$ maximum unbalance per string) is reached at half season.

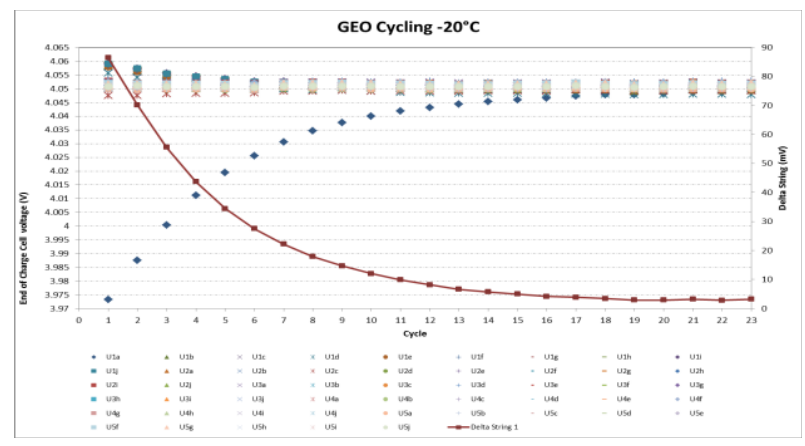

Figure 8. GEO balancing test performed on 10S5P VES16 Battery with string unbalanced.

This balancing system is fully autonomous and requires no command or telemetries.

The Power Conditioning and Distribution Unit (PCDU) is thus simplified as compared to a solution with high capacity cells such as VES180SA cells (voltage of each packs of cells in parallel shall be monitored, command is necessary for managing by-pass, balancing system is implemented in the PCDU if not integrated in the battery). 


\section{GEO APPLICATIONS WITH VES16 CELLS}

Saft is currently working on two GEO applications where the VES16 cell has been selected (Tab. 2), and probably more in the near future.

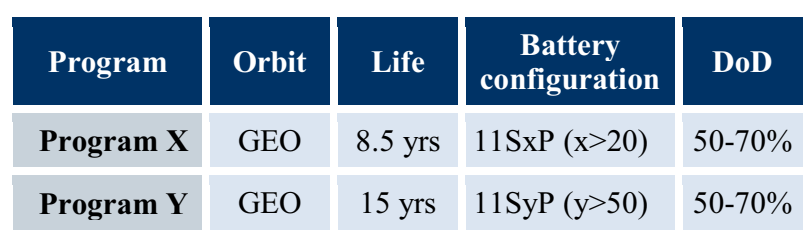

Table 2. VES16 Li-ion Batteries for GEO applications.

These programs are roughly presented in sections 4.1 and 4.2. Section 4.3 will give a trade-off between a VES16 battery and a VES180SA battery that we could propose for a small GEO application (study case).

\subsection{Program $X$}

For this program, the choice of VES16 cells has been driven by the atypical mission profile especially due to a long term period storage of more than 10 years. Considering the acceptance and integration activities, the on-ground lifetime reaches 16 years.

At the End of Life (EoL), i.e. after the on-ground period and the in-orbit period of 8.5 years, the $11 \mathrm{~S} 24 \mathrm{P}$ battery sized to fulfil this mission ( $\mathrm{DoD}>50 \%$ ) is predicted to have less than $7 \%$ of energy losses EoL.

Regarding the design, the 11SxP battery is composed of four modules, connected in parallel. A junction box is fitted on one of the modules for proposing a single electrical interface. Interconnection harness is included in the battery.

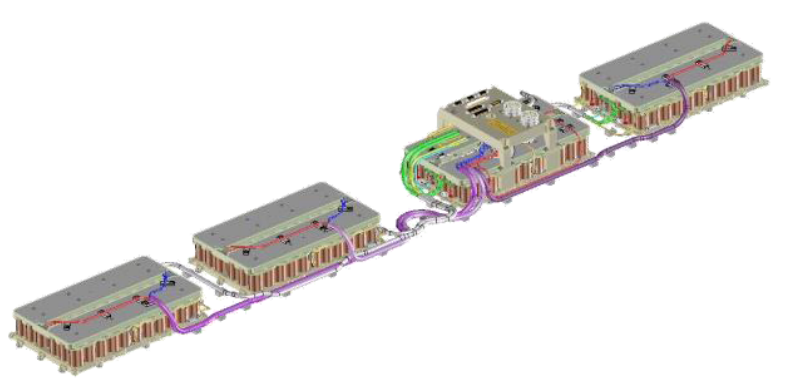

Figure 9. Illustration of the 11SxP battery.

\begin{tabular}{|l|c|c|}
\hline \multicolumn{2}{|c|}{ Dimensions of one module } & $\begin{array}{c}\text { Weight of } \\
\text { battery }\end{array}$ \\
\hline Length & $408 \mathrm{~mm}$ & \\
\hline Width & $240 \mathrm{~mm}$ & \multirow{2}{*}{$42.0 \mathrm{~kg}$} \\
\hline Height without Junction Box & $98 \mathrm{~mm}$ & \\
\hline Height with Junction Box & $160 \mathrm{~mm}$ & \\
\hline
\end{tabular}

Table 3. Dimensions and weight of the 11SxP VES16 battery.

\subsection{Program $Y$}

For this GEO mission, Saft is currently designing an 11 SyP battery, able to provide up to $7 \mathrm{~kW}$ (DoD of 50$70 \%$ ), for a life-time of 15 years (30 seasons).

The Battery is composed of four identical battery packs (Fig. 10) to be connected in parallel.

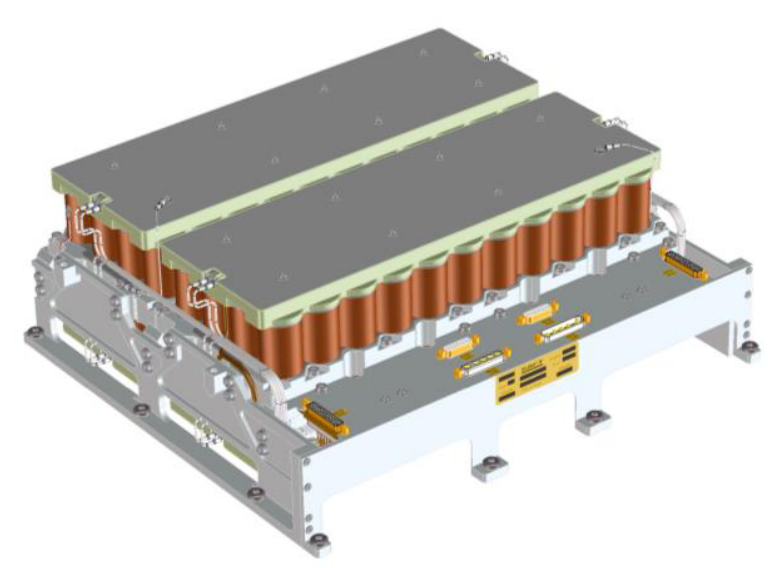

Figure 10. Illustration of the battery pack.

\begin{tabular}{|c|c|c|}
\hline \multicolumn{2}{|c|}{ Dimensions } & Weight \\
\hline Length & $454 \mathrm{~mm}$ & \\
\hline Width & $338 \mathrm{~mm}$ & $24.8 \mathrm{~kg}$ \\
\hline Height & $163 \mathrm{~mm}$ & \\
\hline
\end{tabular}

Table 4. Dimensions and weight of the battery pack.

Both batteries requires no specific commands, they are interfaced with power connectors and telemetry connectors (voltage, temperature, heaters if any).

For the voltage, intermediate measurement like half string voltages is implemented to assess battery health along life on ground.

The combination of available calendar tests and cycling tests are very helpful to accurately design life in orbit either in solstice or equinox periods with a VES16 battery.

\subsection{Trade-off design}

As an example, we could imagine a small GEO mission which would be defined as follows:

- $\quad$ AIT and storage: 3 years @20 $2{ }^{\circ} \mathrm{C}$

- Mission: 10 years @ $20^{\circ} \mathrm{C}$ during eclipses seasons and $10^{\circ} \mathrm{C}$ during solstices periods

- Discharge power during eclipses: $1500 \mathrm{~W}$ 
- Eclipse seasons: 45 eclipses, the longest one lasting 72 minutes

- Battery voltage range: [38.4 V - 49.2 V]

- Maximum DoD: $80 \%$

With a VES16 solution, a 12S12P battery (Fig. 11) allows to fulfil the proposed mission.

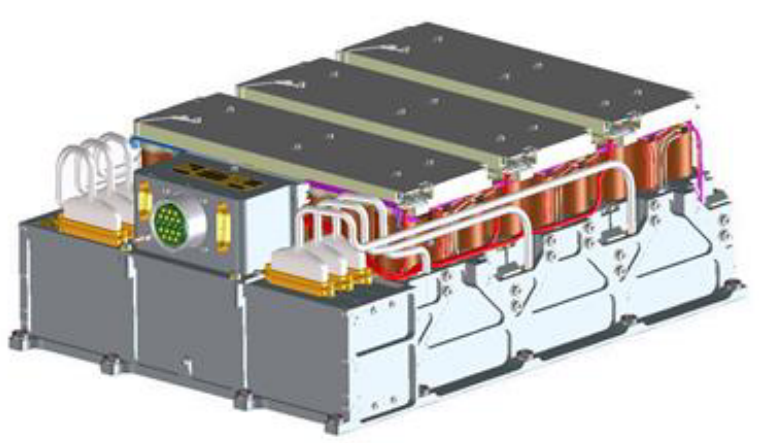

Figure 11. Illustration of the 12S12P VES16 battery.

The maximum DoD is $79 \%$. The energy losses at EoL are less than $3 \%$.

Physical characteristics of the 12S12P VES16 battery are as follows:

\begin{tabular}{|l|r|r|}
\hline \multicolumn{2}{|c|}{ Dimensions } & Weight \\
\hline Length & $454 \mathrm{~mm}$ & \\
\hline Width & $338 \mathrm{~mm}$ & $24.8 \mathrm{~kg}$ \\
\hline Height & $163 \mathrm{~mm}$ & \\
\hline
\end{tabular}

Table 5. Dimensions and weight of the 12S12P VES16 battery.

With a VES180SA solution, the sizing shows that a 2P12S battery (Fig. 12) is necessary.

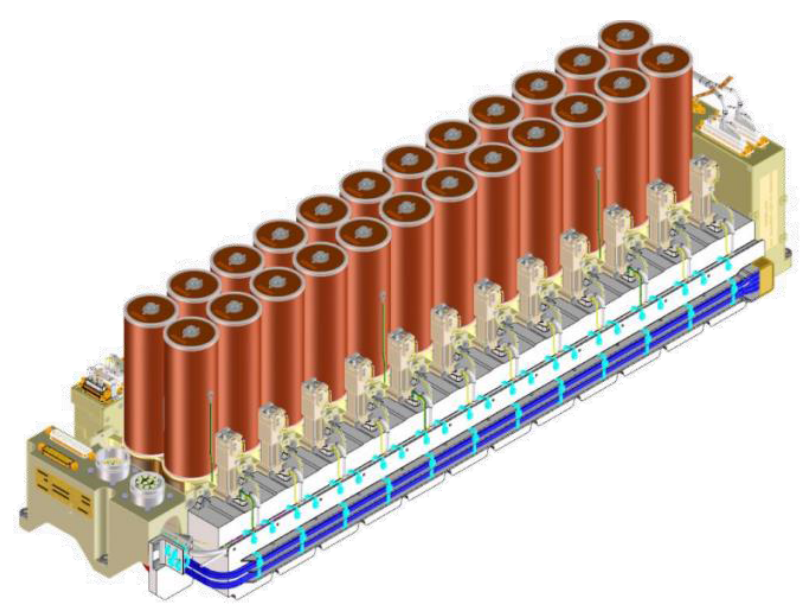

Figure 12. Illustration of the 2P12SVES180SA battery.
The maximum DoD is $44 \%$. The energy losses at EoL are about $1 \%$.

Physical characteristics of the 2P12S VES180SA battery are the followings:

\begin{tabular}{|c|c|c|}
\hline \multicolumn{2}{|c|}{ Dimensions } & Weight \\
\hline Length & $872 \mathrm{~mm}$ & \\
\hline Width & $270 \mathrm{~mm}$ & $43.7 \mathrm{~kg}$ \\
\hline Height & $269 \mathrm{~mm}$ & \\
\hline
\end{tabular}

Table 6. Dimensions and weight of the $2 P 12 S$ VES180SA battery.

With this simple study case, we can see that a VES16 solution can be preferable for a small GEO mission, offering a smaller and lighter battery, requiring nor telemetry or command.

Of course, this trade-off is dependent on platform level features. The result of the trade-off is also depending on the capacity needed by the battery sizing, i.e. if you are far or not from a multiple of large capacity cell. Assuming that a VES180 is equivalent to 10 VES16 in parallel, you can figure out which capacity points are more interesting in VES16 or VES180.

Based on the modularity of VES16 batteries, there is no technical limit to achieve a very large configuration as for example $30 \mathrm{~kW}$, but however, we consider that $10 \mathrm{~kW}$ virtual limit is relevant to question the use of VES16 battery in GEO spacecraft.

It can be as well identified some interesting product lines commonalities, between GEO and LEO batteries solutions at prime level. Said differently: same product, 2 types of missions, GEO and LEO.

\section{REFERENCES}

1. Remy, S., Prevot, D., Reulier, D. \& Vigier, F. (2011). VES16 Li-ion cell for satellites. $9^{\text {th }}$ European Space Power Conference.

2. Remy, S., Mosset, E., Lefeuvre, S. \& Nestoridi, M. (2014). VES16 Li-ion batteries range qualification. $10^{\text {th }}$ European Space Power Conference.

3. Prevot, D., Borthomieu, Y., Malet, F., Rebuffel, C., Carre, A. \& Cenac-Morthe, C. (2016). Saft solutions for full GEO electric propulsion. $11^{\text {th }}$ European Space Power Conference.

4. Nestoridi, M., Mourra, O., Mosset, E., Lefeuvre, S. (2014). Effect of an induced cell soft-short at VES16 battery module. $11^{\text {th }}$ European Space Power Conference. 